Article

\title{
Design of a Compact Dual-Band MIMO Antenna System with High-Diversity Gain Performance in Both Frequency Bands
}

\author{
Wazie M. Abdulkawi ${ }^{1, *,+}$, Waqar Ahmad Malik ${ }^{2, *,+}$, Sajjad Ur Rehman ${ }^{3,+}$, Abdul Aziz ${ }^{4,+}(\mathbb{D}$, \\ Abdel Fattah A. Sheta ${ }^{1,+}$ and Majeed A. Alkanhal ${ }^{1}{ }^{(D}$ \\ 1 Electrical Engineering Department, King Saud University, Riyadh 11451, Saudi Arabia; \\ asheta@ksu.edu.sa (A.F.A.S.); majeed@ksu.edu.sa (M.A.A.) \\ 2 Electrical Engineering Department, Abasyn University, Islamabad 44000, Pakistan \\ 3 Electrical Engineering Department, Namal Institute Mianwali, Mianwali 42250, Pakistan; \\ sajjad.rehman@namal.edu.pk \\ 4 Telecommunication Engineering Department, The Islamia University of Bahawalpur, Bahawalpur 63100, \\ Pakistan; abdul.aziz@iub.edu.pk \\ * Correspondence: walkadri@ksu.edu.sa (W.M.A.); waqar@ieee.org (W.A.M.) \\ + These authors contributed equally to this work.
}

Citation: Abdulkawi, W.M.; Malik, W.A.; Rehman, S.U., Aziz, A.; Sheta, A.F.A.; Alkanhal, M.A. Design of a Compact Dual-Band MIMO Antenna System with High-Diversity Gain Performance in Both Frequency Bands. Micromachines 2021, 12, 383. https://doi.org/10.3390/mi12040383

Academic Editor: Mark L. Adams

Received: 11 March 2021

Accepted: 23 March 2021

Published: 1 April 2021

Publisher's Note: MDPI stays neutral with regard to jurisdictional claims in published maps and institutional affiliations.

Copyright: (c) 2021 by the authors. Licensee MDPI, Basel, Switzerland. This article is an open access article distributed under the terms and conditions of the Creative Commons Attribution (CC BY) license (https:// creativecommons.org/licenses/by/ $4.0 /)$.
Abstract: A compact four-element dual-band multiple-input and multiple-output (MIMO) antenna system is proposed to achieve high isolation and low channel capacity loss. The MIMO antenna was designed and optimized to cover the dual-frequency bands; the first frequency band is a wide band, and it covers the frequency range of $1550-2650 \mathrm{MHz}$, while the other frequency band covers the 3350-3650 MHz range. The measured wide-band impedance bandwidths of $1.1 \mathrm{GHz}$ and $300 \mathrm{MHz}$ were achieved in the lower and upper frequency bands, respectively. The proposed structure consists of four novel antenna elements, along with a plus-sign-shaped ground structure on an FR4 substrate. The overall electrical size of the whole dual-band MIMO antenna system is $0.3 \lambda(\mathrm{W}) \times 0.3 \lambda(\mathrm{L}) \times$ $0.008 \lambda(\mathrm{H})$ for the lower frequency band. It achieved greater than 10 and $19 \mathrm{~dB}$ isolation in the lower and upper frequency bands, respectively. The antenna system accomplished an envelope correlation coefficient of $|\rho| \leq 0.08$ in the lower frequency band, while it achieved $|\rho| \leq 0.02$ in the higher frequency band. The computed channel capacity loss remained less than almost $0.4 \mathrm{bits} / \mathrm{s} / \mathrm{Hz}$ in both frequency bands. Therefore, it achieved good performance in both frequency bands, with the additional advantage of a compact size. The proposed MIMO antenna is suitable for compact handheld devices and smartphones used for GSM (Global System for Mobiles), UMTS (Universal Mobile Telecommunications Service), WCDMA (Wideband Code Division Multiple Access), LTE (Long Term Evolution), 5G sub-6 GHz, PCS (Personal Communications Service), and WLAN (wireless local area network) applications.

Keywords: 5G communication; channel capacity loss; diversity gain; envelope correlation coefficient (ECC); MIMO antenna; multi-band antenna

\section{Introduction}

Multiple-input and multiple-output (MIMO) technology is identified as the key technology for $5 \mathrm{G}$ communication, as it enables systems to achieve peak data rates and higher spectral efficiency [1-5]. In addition, it also offers a significant capacity gain over conventional single-input-single-output (SISO) systems [6,7]. As compared to an SISO antenna system, the MIMO antenna system is more resistant to noise and fading channel conditions (which is a more realistic channel condition). An MIMO technology results in higher gain, bandwidths, channel capacity, and diversity performance as compared to SISO technology. MIMO technology has lower channel capacity loss, which results in a higher data rate without losing additional spectrum and transmitted power.

The main design challenges of MIMO antenna systems for handheld devices are, firstly, the compactness due to limited space and, secondly, the reduced coupling between 
the antenna elements. Despite the fact that an MIMO antenna system increases the theoretical capacity of the system, it is degraded if the signals received at different antenna elements are correlated [8]. The system fails to provide the diversity gain if the envelope correlation coefficient $(\rho)$ exceeds 0.5 [9]. The value of $|\rho| \leq 0.3$ is good enough to achieve diversity gain.

Several four-element MIMO antenna systems have been presented in literature to cover $5 \mathrm{G}$ as well as $2 \mathrm{G}, 3 \mathrm{G}$, and $4 \mathrm{G}$ frequency bands [10-19]. In [10], a four-element dualband MIMO antenna system was proposed to cover two frequency bands, i.e., 734-790 and 2307-2475 MHz. A partial ground was utilized for the structure to achieve isolation of better than 5 and $10 \mathrm{~dB}$ for the lower and upper frequency bands, respectively. The overall dimensions of the proposed antenna system were $58 \times 110 \times 1.6 \mathrm{~mm}^{3}$. Another four-element MIMO antenna for a mobile handset was proposed in [11], which resonated for 3415-3590 MHz. The proposed antenna size was $40.8 \times 3 \mathrm{~mm}^{2}$, while the edge-to-edge distance between adjacent antenna elements was only $1 \mathrm{~mm}$, and it achieved greater than 11.6 dB isolation. Furthermore, the effect of adding an inductor and a capacitor to reduce mutual coupling was also presented. In [12], a tri-band MIMO antenna for 4G and 5G mobile terminals was reported. The antenna had overall dimensions of $75 \times 150 \times 1.6 \mathrm{~mm}^{3}$, and it covered the frequency ranges of 2.5-2.7, 3.45-3.8, and 5.00-5.45 GHz. The gain achieved was $>5 \mathrm{dBi}$, while the isolation was better than $17 \mathrm{~dB}$ for all of the frequency bands. In [13], a compact dual-band (1.87-2.53 and 26-28 GHz) 4G MIMO antenna was proposed, which achieved greater than 15 and $25 \mathrm{~dB}$ isolation, while the achieved gain was 4 and $8 \mathrm{dBi}$, respectively. The dimensions of the proposed MIMO system were $60 \times 30 \times 0.965 \mathrm{~mm}^{3}$. Another compact $4 \times 4 \mathrm{MIMO}$ antenna system was proposed in [20] for $4 \mathrm{G}$ applications; in this case, each non-resonant antenna element size was $12 \times 3 \times 2.4 \mathrm{~mm}^{3}$. However, creating a high-performance and compact multi-band MIMO antenna that may cover 5G as well as $4 \mathrm{G}$ frequency bands is still a challenging task.

In this work, a novel and compact four-element dual-band MIMO antenna system is proposed, which covers the ranges of the 1550-2650 and 3350-3650 MHz frequency bands. The antenna system achieved the low envelope correlation coefficients of $\left|\rho_{L}\right| \leq 0.08$ and $\left|\rho_{U}\right| \leq 0.02$ at the lower and upper frequency bands, respectively; hence, it fulfills the requirements of the diversity gain. The isolation between antenna elements is better than 10 and $19 \mathrm{~dB}$ in the lower and higher frequency bands, respectively.The overall electrical size of the antenna system at the lower value of the lower frequency band is $0.3 \lambda(\mathrm{W}) \times$ $0.3 \lambda(\mathrm{L}) \times 0.008 \lambda(\mathrm{H})$, so the proposed MIMO antenna achieves good performance in both frequency bands, with the additional advantage of compact size.

\section{Design of the Dual-Band MIMO Antenna System}

The layout of the proposed four-element MIMO antenna system is shown in Figure 1. The antenna was designed and optimized using the High-Frequency Structure Simulator (HFSS Ver. 13). The antenna system consisted of a plus-sign-shaped ground structure on the bottom side of the FR4 substrate with a dielectric constant of 4.2 and thickness of $1.6 \mathrm{~mm}$. Four patch elements were printed on the top side of the substrate to achieve a four-element MIMO antenna system. The antenna dimensions are given in Table 1 . The overall size of the antenna system was $58 \mathrm{~mm}(\mathrm{~W}) \times 60 \mathrm{~mm}(\mathrm{~L}) \times 1.6 \mathrm{~mm}(\mathrm{H})$. Every element of the designed MIMO system was a coaxial probe fed through a 50 ohm SMA (SubMiniature version A) connector.

\subsection{Development Steps to Achieve a Dual-Band MIMO Antenna}

Firstly, a simple elliptical-shaped single-band patch element with a partial ground was selected to achieve compactness. The four elements were arranged in an orthogonal arrangement around a plus-shaped partial ground to achieve higher isolation between antenna elements of the MIMO antenna system. Two opposite slots were introduced into each element to reduce the size of the element and transform it into a multi-band antenna element. The sizes of the patch elements and lengths of the slots were optimized using 
parametric analysis in order to achieve a compact multi-band MIMO antenna system with a high diversity gain performance.

Table 1. Parameters of the dual-band multiple-input and multiple-output (MIMO) antenna.

\begin{tabular}{cc}
\hline \multicolumn{3}{c}{ All Dimensions Are in $\mathbf{~ m m}$} \\
\hline $\mathrm{Wg}=5$ & $\mathrm{~L} 5=9.89$ \\
$\mathrm{Wt}=2.82$ & $\mathrm{~L} 6=12.02$ \\
$\mathrm{~W} 1=2$ & $\mathrm{~L} 7=11.58$ \\
$\mathrm{~W} 2=\mathrm{W} 3=1.41$ & $\mathrm{~L} 8=7.77$ \\
$\mathrm{~W} 4=2$ & $\mathrm{~L} 9=5.5$ \\
$\mathrm{~L} 1=17$ & $\mathrm{~L} 10=7.07$ \\
$\mathrm{~L} 2=12$ & $\mathrm{~L} 11=4.5$ \\
$\mathrm{~L} 3=11$ & $\mathrm{~L} 12=1$ \\
$\mathrm{~L} 4=10.59$ & $\mathrm{~L} 13=2$ \\
\hline
\end{tabular}

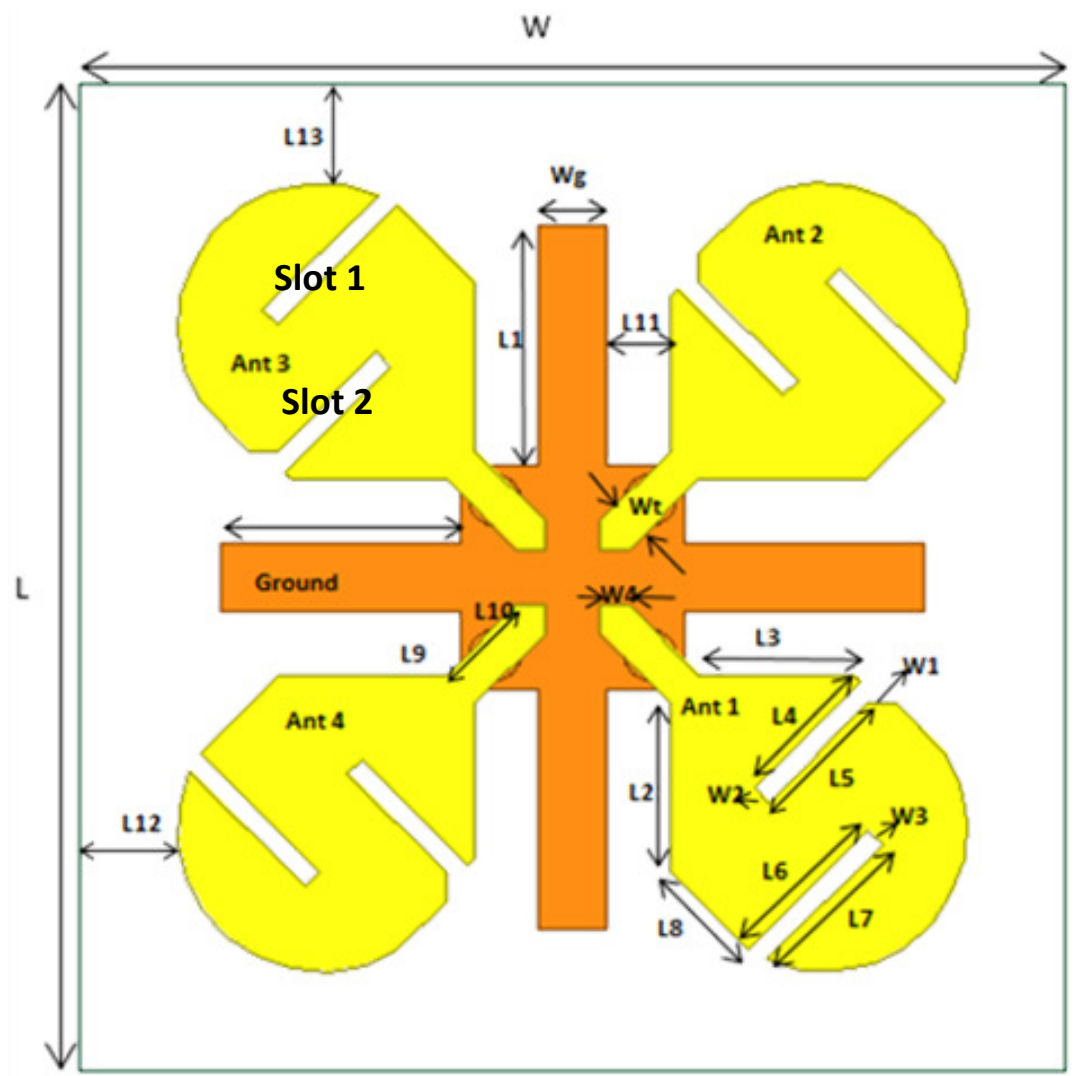

Figure 1. Geometry of the four-element MIMO antenna system.

The development steps for the dual-band MIMO antenna are shown in Figure 2a-c. The s-parameter response of the four-element MIMO antenna without any slots is shown in Figure 3. It can be seen that the basic patch element of step (a) has a single resonance notch with a very low impedance bandwidth. Therefore, two opposite slots were introduced into the basic patch elements to improve the bandwidth and transform these into multi-band antenna elements, as shown in Figure $2 b, c$. The individual and combined effects of both slots broadened the bandwidth at a lower frequency, and also created another resonance notch at $3.5 \mathrm{GHz}$, which is evident from Figure 3. 


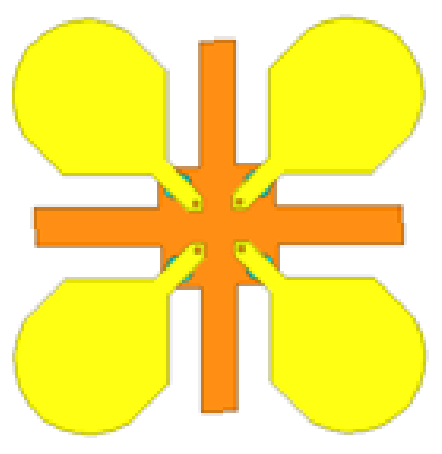

(a)

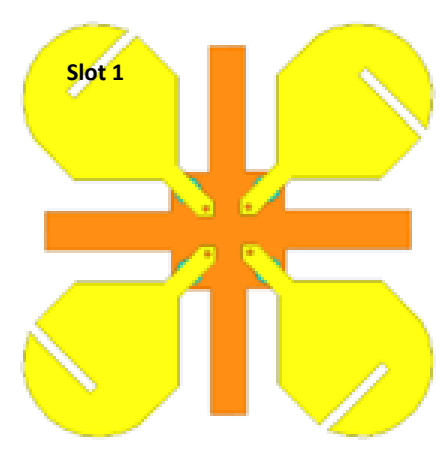

(b)

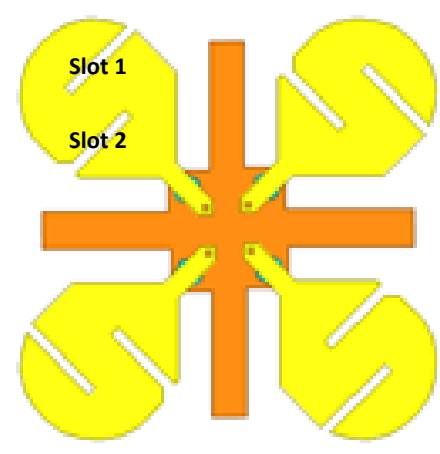

(c)

Figure 2. Development steps to achieve dual-band MIMO antenna (a) basic elements without slot, (b) elements with slot 1 , (c) elements with slots 1 and 2.

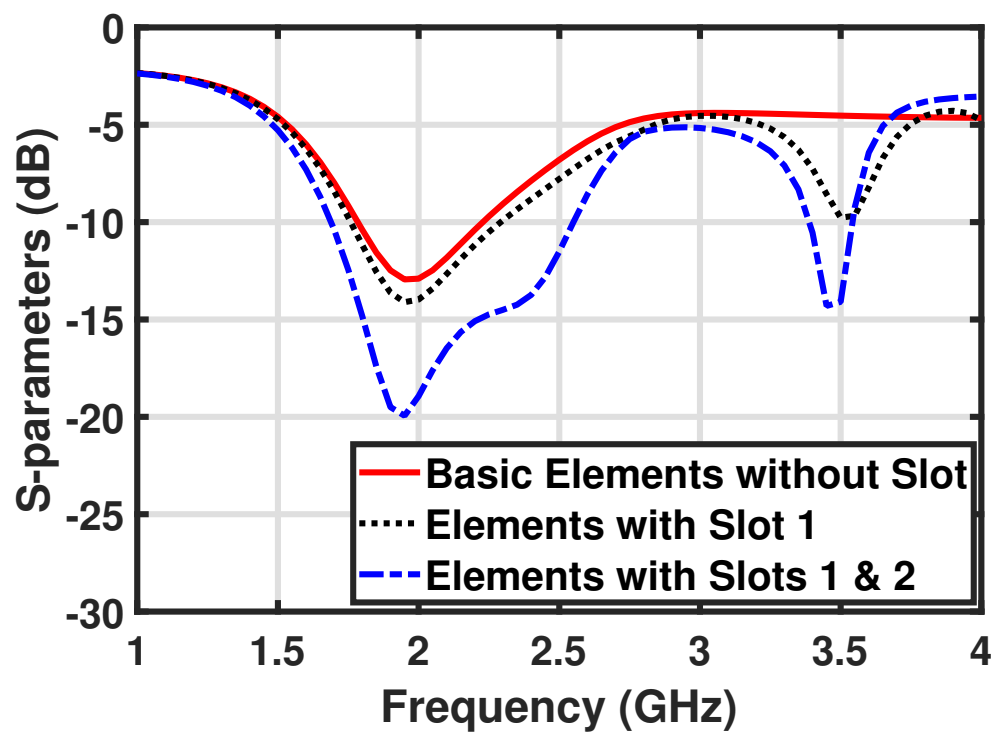

Figure 3. S-parameters for each development step for the dual-band MIMO antenna.

The partial ground consisted of a plus-sign-shaped structure and played an important role in achieving a higher degree of isolation among all antenna elements. The width $(\mathrm{Wg})$ of the ground structure was optimized to achieve higher isolation. A lower value of the $\mathrm{Wg}$ provided good isolation between the elements, and vice versa. The attained optimized value of $\mathrm{Wg}$ was equal to $5 \mathrm{~mm}$. The optimized S-parameters for antenna 1 of the dual-band MIMO antenna are shown in Figure 4. All of the S-parameters of each antenna element were expected to be the same due to the symmetry of all antenna elements with respect to other elements, so the S-parameters for antenna 1 are shown here for brevity. The final optimized MIMO antenna covered dual frequency bands; the first band was a wide band of frequencies from 1550 to $2650 \mathrm{MHz}$, that covered 2G, 3G, 4G, and several 5G sub-6GHz bands, while the upper frequency band also covered the most common $3.5 \mathrm{GHz}$ frequency band, 3350-3650 MHz, for 5G applications. All of the coupling S-parameters-S21, S31, and S41-remained below - $10 \mathrm{~dB}$ in the lower frequency band, while these were below $-19 \mathrm{~dB}$ for the higher frequency band, which is suitable for existing $2 \mathrm{G}, 3 \mathrm{G}$, and $4 \mathrm{G}$, as well as for upcoming $5 \mathrm{G}$ applications. 


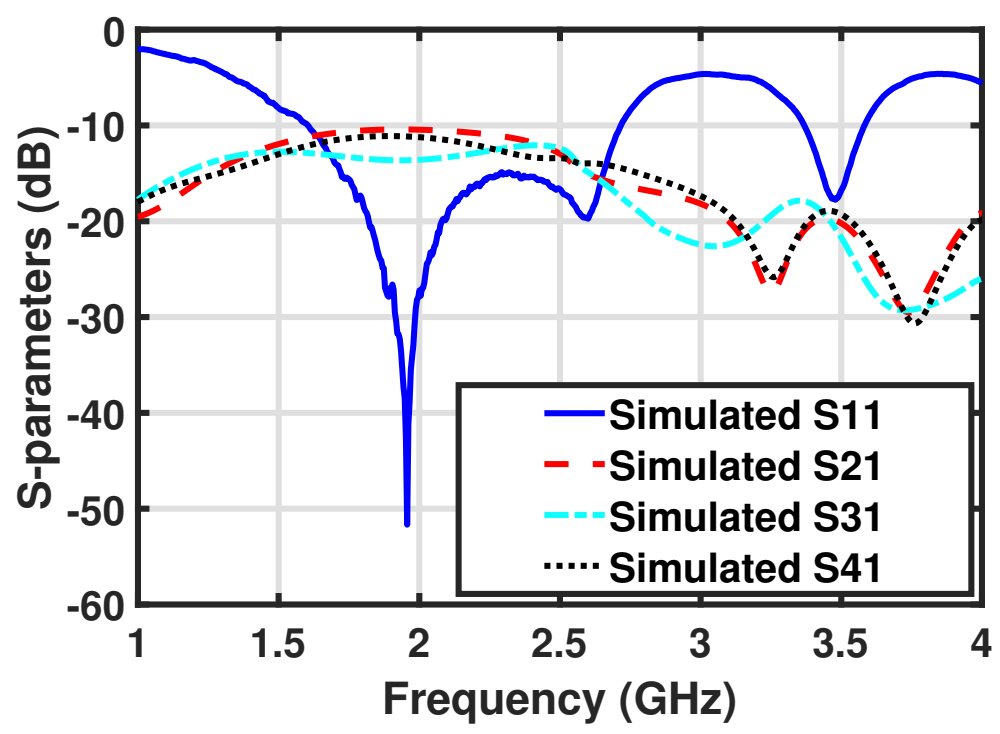

Figure 4. S-parameters for antenna 1 of the optimized dual-band MIMO antenna.

Figure 5 shows the surface current distribution on the antenna elements at $2.1 \mathrm{GHz}$ when Ant- 1 is excited and other antennas are considered to be matched to the $50 \mathrm{ohm}$ load. It can be seen that the surface current density on Ant- 1 is at its maximum, while other antennas are almost isolated from Ant-1. A similar isolation performance was also seen for a surface current distribution at $3.5 \mathrm{GHz}$, which is not shown here for brevity.

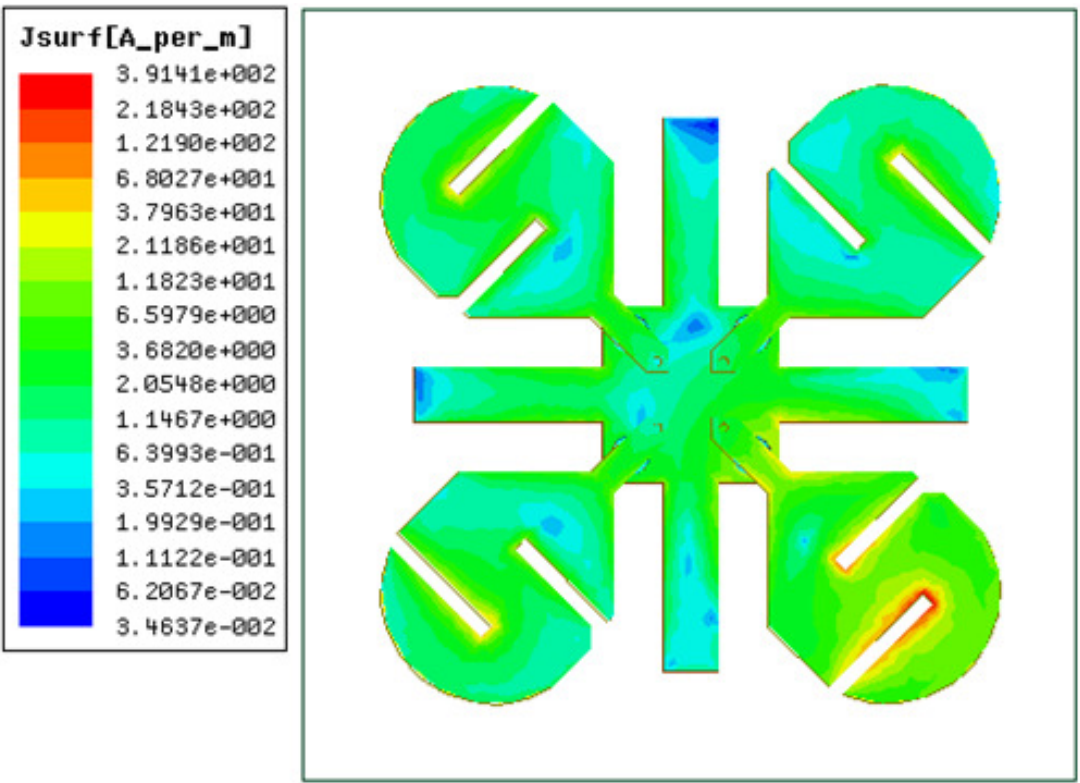

Figure 5. Surface current distribution on the MIMO antenna system when Ant-1 is excited.

\subsection{Fabrication of the Prototype}

A prototype of a dual-band MIMO antenna was fabricated and measured in order to verify the simulation results. The prototype is shown in Figure 6. It can be seen that all three remaining ports were matched with a $50 \mathrm{ohm}$ load during the measurement of the S-parameters for antenna 1. The fabricated prototype was tested using an Anritsu Vector Network Analyzer (VNA 37369C). A comparison of the simulated and measured scattering parameters for antenna 1 of the dual-band MIMO antenna is shown in Figure 7. It can be seen that the measured results of the S-parameters are very well matched with the simulated results. Each antenna covers the same dual band with almost the same frequency 
ranges. The measured results also depict a similarly high isolation between the antenna elements in both frequency bands. This, in turn, verifies the suitability of the proposed dual-band antenna for MIMO applications. Some minor deviations in the S-parameters are seen due to fabrication and measurement tolerance.

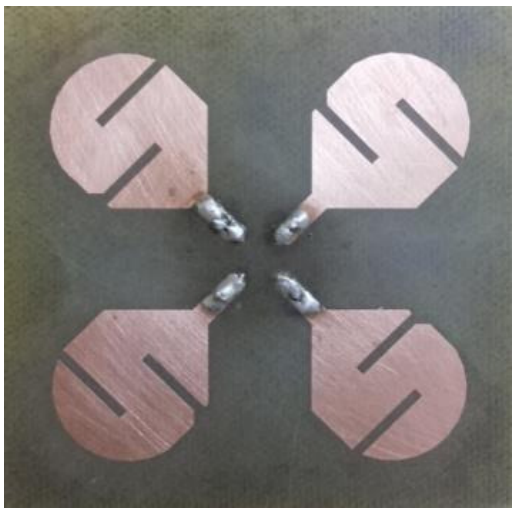

(a)

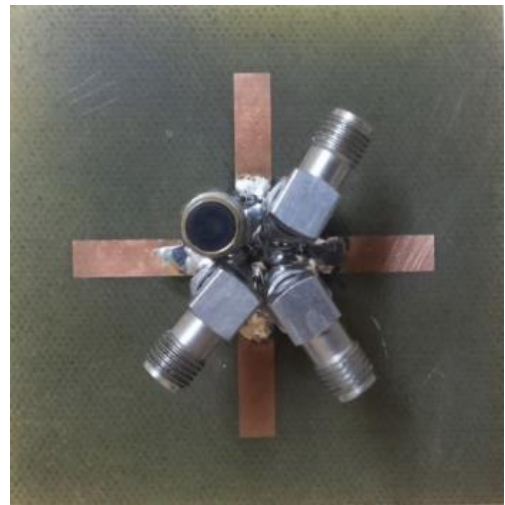

(b)

Figure 6. Fabricated prototype of the MIMO antenna system: (a) top side; (b) bottom side.

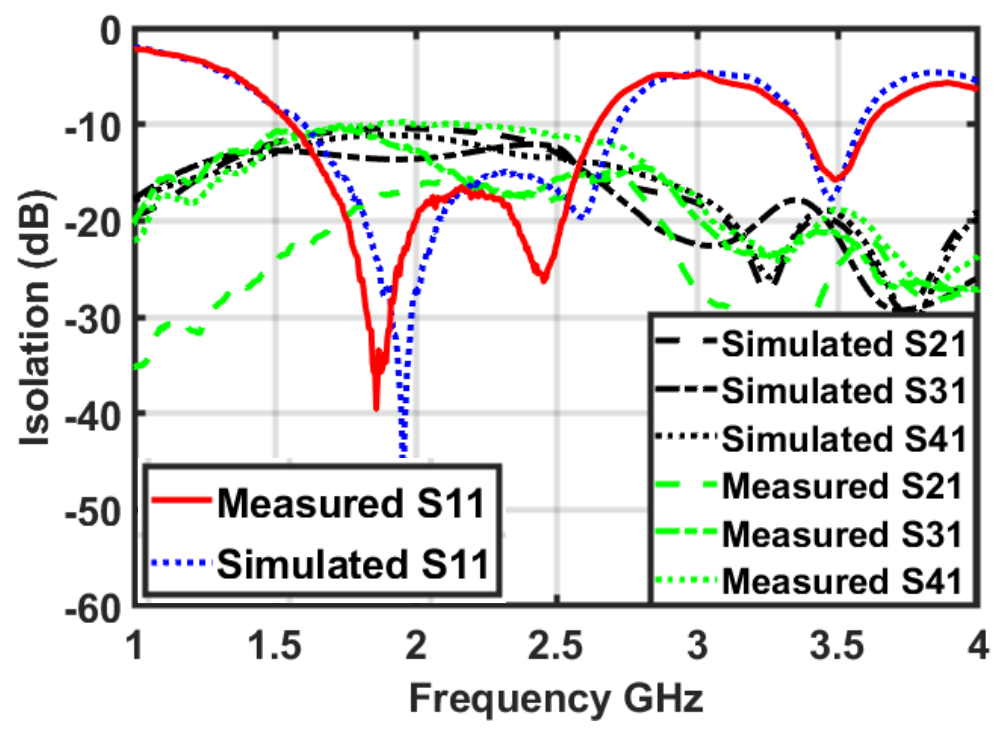

Figure 7. Simulated and measured S-parameters of the dual-band MIMO antenna system.

\section{Dual-Band MIMO Antenna Performance}

In order to justify the performance of the proposed MIMO antenna, some important diversity parameters, such as the envelope correlation coefficient $(\rho)$ and channel capacity loss (CCL), had to be calculated and verified.

\subsection{Envelope Correlation Coefficient}

The envelope correlation coefficient $(\rho)$ is a measure of the diversity performance of any MIMO antenna system. In an MIMO antenna system, $\rho$ shows the influence of diverse signals that reach the antenna elements by following distinct propagation paths. The value of " $\rho$ " is calculated using the S-parameters, according to [21], using:

$$
\rho_{i j}=\frac{\left|S_{i i}{ }^{*} S_{i j}+S_{j i}{ }^{*} S_{j j}\right|^{2}}{\left(1-\left|S_{i i}\right|^{2}-\left|S_{j i}\right|^{2}\right)\left(1-\left|S_{j j}\right|^{2}-\left|S_{i j}\right|^{2}\right)^{2}},
$$

where $i=1$ and $j=2,3$, and 4 in our case, thus resulting in the resultant values of $\rho_{12}, \rho_{13}$, and $\rho_{14}$. A higher value of the envelope correlation coefficient $(\rho)$ degrades the spectral 
efficiency of any MIMO antenna system. Therefore, it is desirable to achieve a correlation coefficient that is as low as possible. A quite perfect performance is experienced in an MIMO antenna system when the value of " $\rho$ " approaches zero [21].

A value of the envelope correlation coefficient of $|\rho| \leq 0.3$ is considered good enough to provide high diversity gain in an MIMO antenna system. Figure 8 shows the envelope correlation coefficient curves for the covered frequency bands. As is evident from the figure, the proposed design has a maximum correlation coefficient of 0.08 in the lower frequency band, while it remains below 0.02 in the higher frequency band for all values of $i$ and $j$, which is suitable for $4 \mathrm{G}$ and $5 \mathrm{G}$ communication.

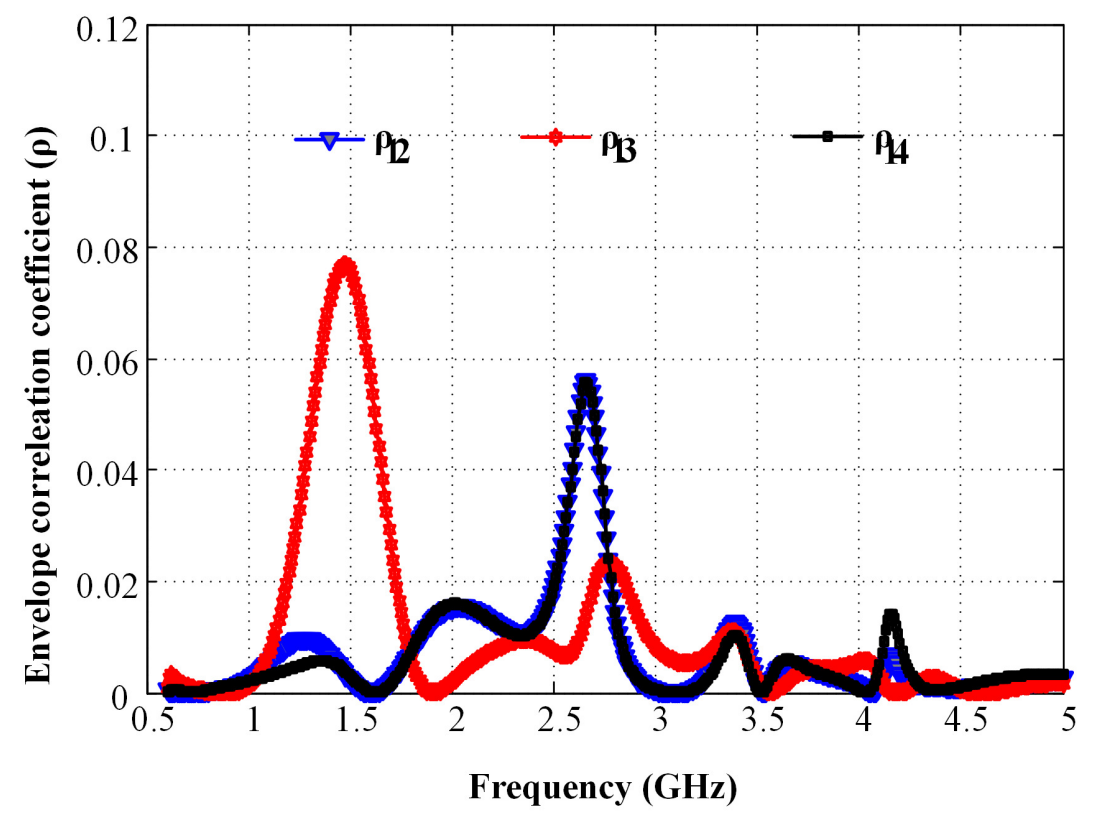

Figure 8. Measured performance for the envelope correlation coefficient (ECC).

\subsection{Channel Capacity Loss}

The channel capacity loss (CCL) is also one of the important diversity performance inspection parameters for MIMO antennas. It describes the maximum attainable limit of the information transmission rate up to which the signal can be easily transferred without a significant loss. The CCL can be calculated using the following set of equations [22]:

$$
C C L=-\log _{2} \operatorname{det}(\boldsymbol{\alpha})
$$

where

$$
\boldsymbol{\alpha}=\left[\begin{array}{llll}
\alpha_{11} & \alpha_{12} & \alpha_{13} & \alpha_{14} \\
\alpha_{21} & \alpha_{22} & \alpha_{23} & \alpha_{24} \\
\alpha_{31} & \alpha_{32} & \alpha_{33} & \alpha_{34} \\
\alpha_{41} & \alpha_{42} & \alpha_{43} & \alpha_{44}
\end{array}\right]
$$

and

$$
\alpha_{i i}=1-\left(\sum_{j=1}^{M}\left|S_{i j}\right|^{2}\right), \alpha_{i j}=-\left|S_{i i}{ }^{*} S_{i j}+S_{j i}{ }^{*} S_{j j}\right| .
$$

The CCL computed for the proposed antenna is demonstrated in Figure 9. It can be seen that the calculated CCL is almost below the standard value of $0.4 \mathrm{bits} / \mathrm{s} / \mathrm{Hz}$ for a practical MIMO antenna system [22] in both frequency bands. 


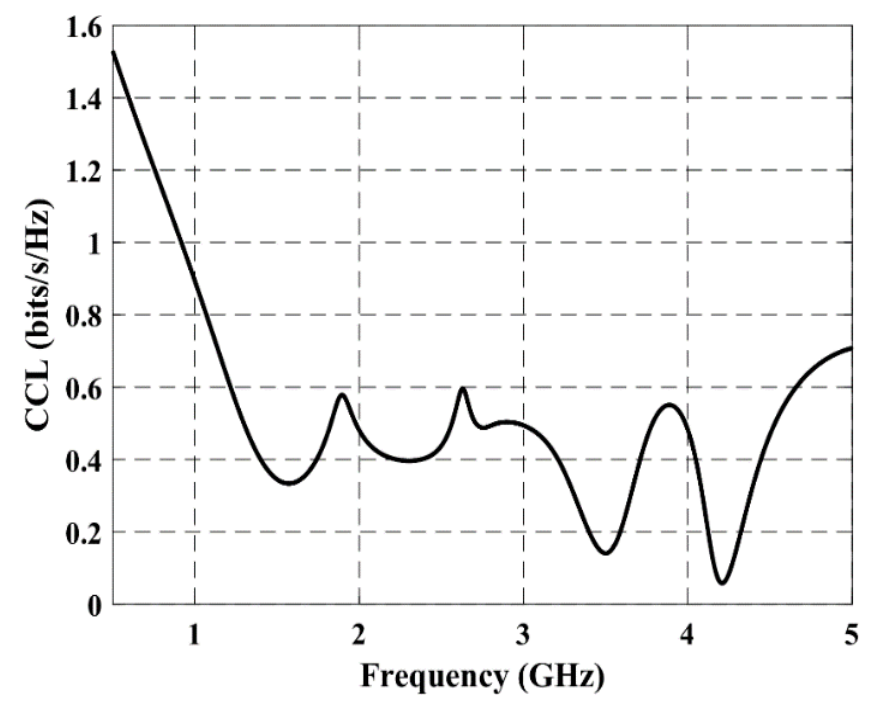

Figure 9. Measured performance for the channel capacity loss (CCL).

\subsection{Radiation Patterns}

The simulated and measured E- and H-plane radiation patterns at 1.8, 2.4, and $3.5 \mathrm{GHz}$ are shown in Figure 10. A time-domain antenna measurement system, GEOZONDASAMS [23], was used to measure the radiation pattern for the proposed MIMO antenna elements. As is evident, a good agreement between the simulation and measured results is observed. As can be noticed, the radiation pattern is consistently omni-directional at different resonant frequencies, and is thus suitable for use in most of the $4 \mathrm{G}$ and $5 \mathrm{G}$ sub$6 \mathrm{GHz}$ bands. The peak gains of antenna 1 are $2.2 \mathrm{~dB}$ at $1.8 \mathrm{GHz}, 2.7 \mathrm{~dB}$ at $2.4 \mathrm{GHz}$, and $3.8 \mathrm{~dB}$ at $3.5 \mathrm{GHz}$. Almost similar radiation patterns and performance are observed for antenna 2 , antenna 3 , and antenna 4 , which are not shown here for brevity.

\subsection{Comparison with Previous Works}

The performance of the proposed dual-band antenna was also compared with recent previous works to highlight the significance of the proposed dual-band MIMO antenna; see Table 2. It can be seen that the proposed dual-band MIMO antenna performance was comparable to that found in previous works, with the additional advantage of compact size.

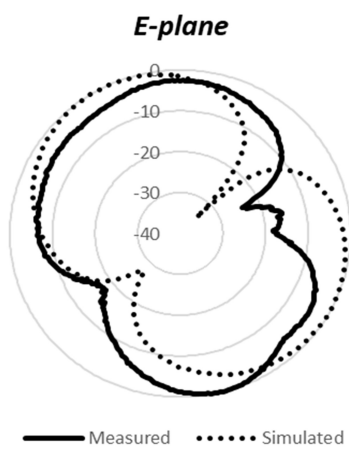

(a)

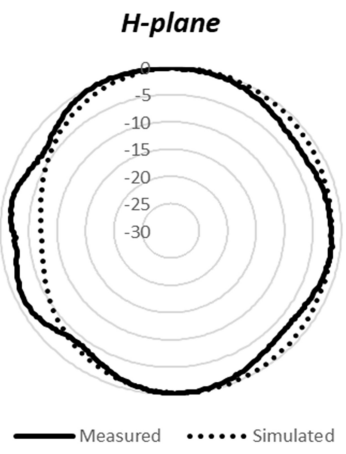

(b)

Figure 10. Cont. 


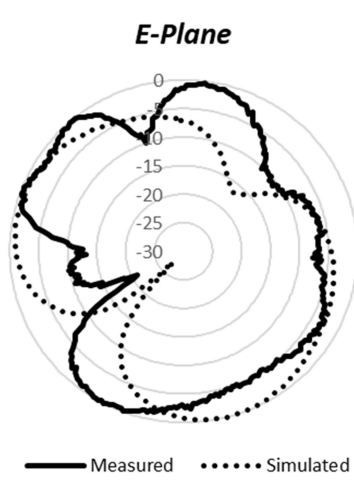

(c)

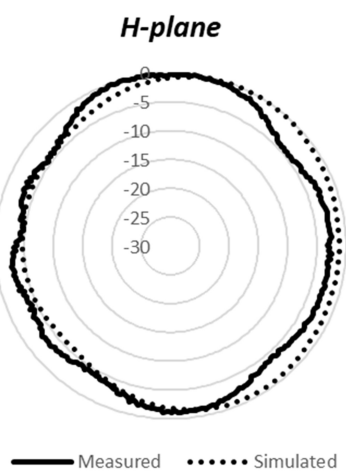

(d)

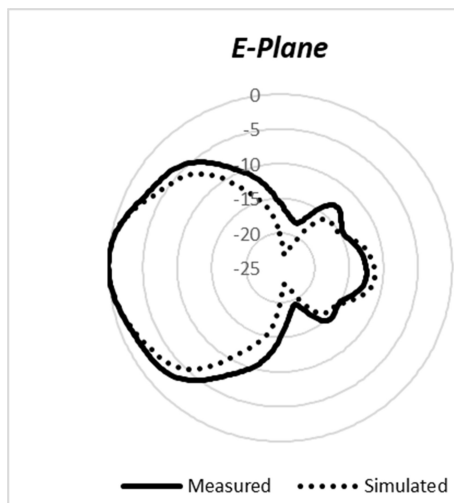

(e)

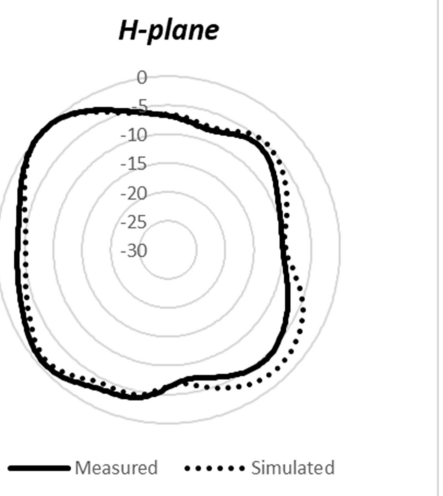

(f)

Figure 10. Measured and simulated radiation patterns. (a) E-plane at $1.8 \mathrm{GHz}$; (b) H-plane at $1.8 \mathrm{GHz}$; (c) E-plane at $2.4 \mathrm{GHz}$; (d) H-plane at $2.4 \mathrm{GHz}$; (e) E-plane at $3.5 \mathrm{GHz}$; (f) H-plane at $3.5 \mathrm{GHz}$.

Table 2. Comparison with previous works.

\begin{tabular}{|c|c|c|c|c|c|}
\hline Reference & $\begin{array}{l}\text { Frequency } \\
\text { (GHz) }\end{array}$ & $\begin{array}{l}\text { Gain } \\
\text { (dBi) }\end{array}$ & $\begin{array}{l}\text { Isolation } \\
\text { (dB) }\end{array}$ & ECC & $\begin{array}{l}\text { Size } \\
\left(\lambda^{2}\right)\end{array}$ \\
\hline [11] & $3.4-3.6$ & - & $>11$ & - & $0.46 \times 0.03$ \\
\hline [12] & $\begin{array}{c}\text { Tri-band } \\
2.5-2.7 \\
3.45-3.8 \\
5.0-5.45\end{array}$ & $\begin{array}{c}2.5 \\
2.77 \\
2.8\end{array}$ & $\begin{array}{l}>19 \\
>23 \\
>17\end{array}$ & $\begin{array}{l}<0.01 \\
<0.001 \\
<0.002\end{array}$ & $0.63 \times 1.25$ \\
\hline [13] & $\begin{array}{c}\text { Dual-Band } \\
1.87-2.53 \\
26-28\end{array}$ & $\begin{array}{c}3.86 \\
8.0\end{array}$ & $\begin{array}{l}>15 \\
>25\end{array}$ & $\begin{array}{l}0.181 \\
\text { NA }\end{array}$ & $0.37 \times 0.62$ \\
\hline [24] & $\begin{array}{c}\text { Tri-band } \\
0.82-0.96 \\
1.710-2.69 \\
3.4-3.6\end{array}$ & $\begin{array}{c}\text { NA } \\
\text { NA } \\
6.5\end{array}$ & $\begin{array}{l}\text { NA } \\
\text { NA } \\
>13\end{array}$ & $\begin{array}{l}\text { NA } \\
\text { NA } \\
<0.07\end{array}$ & $0.41 \times 0.2$ \\
\hline This work & $\begin{array}{c}\text { Dual-Band } \\
1.55-2.65 \\
3.35-3.65\end{array}$ & $\begin{array}{l}2.2 \\
3.8\end{array}$ & $\begin{array}{l}>10 \\
>19\end{array}$ & $\begin{array}{l}<0.08 \\
<0.02\end{array}$ & $0.3 \times 0.31$ \\
\hline
\end{tabular}




\section{Conclusions}

A high-performance, compact, and dual-band MIMO antenna system was proposed for LTE and 5G applications. The overall dimensions of the proposed four-element antenna system are $58 \times 60 \times 1.6 \mathrm{~mm}^{3}$. The antenna covers dual frequency bands: a wide band that is characteristic of the lower frequency band (1550-2650 MHz), which covers 2G, 3G, $4 \mathrm{G}$, and several $5 \mathrm{G}$ sub-6GHz bands, as well as an upper frequency band that covers the most common $3.5 \mathrm{GHz}$ frequency band for $5 \mathrm{G}$ applications. The isolation between antenna elements is $\geq 10 \mathrm{~dB}$ in the lower frequency band, while it is $\geq 19 \mathrm{~dB}$ in the upper frequency band. The computed channel capacity loss is less than almost $0.4 \mathrm{bits} / \mathrm{s} / \mathrm{Hz}$ in both frequency bands. The envelope correlation coefficient is less than 0.08 and 0.02 in the lower and upper frequency bands, respectively. So, the proposed MIMO antenna can fulfill the requirements for $4 \mathrm{G}$ as well as $5 \mathrm{G}$ wireless communication systems.

Author Contributions: Conceptualization, W.A.M. and A.F.A.S.; methodology, W.M.A., W.A.M., S.U.R., A.A., A.F.A.S. and M.A.A.; software, W.M.A., W.A.M., S.U.R. and A.A.; validation, W.A.M.; formal analysis, W.M.A., W.A.M., S.U.R., A.A., A.F.A.S. and M.A.A. and M.A.A.; investigation, A.F.A.S. and M.A.A.; resources, A.F.A.S. and M.A.A.; data curation, W.A.M.; writing-original draft preparation, W.A.M.; writing-review and editing, W.M.A., W.A.M., S.U.R., A.A., A.F.A.S. and M.A.A.; visualization, W.M.A., W.A.M., S.U.R., and A.A.; supervision, A.F.A.S. and M.A.A.; project administration, A.F.A.S.; funding acquisition, A.F.A.S. All authors have read and agreed to the published version of the manuscript.

Funding: This research received no external funding.

Data Availability Statement: The study did not support any data.

Acknowledgments: This Project was funded by the National Plan for Science, Technology and Innovation (MAARIFAH), King Abdulaziz City for Science and Technology, Kingdom of Saudi Arabia, Award Number (15-ELE5017-02).

Conflicts of Interest: The authors declare no conflict of interest.

\section{References}

1. Kanwal, K.; Safdar, G.A.; Ur-Rehman, M.; Yang, X. Energy Management in LTE Networks. IEEE Access 2017, 5, 4264-4284. [CrossRef]

2. Lee, D.J.; Lee, S.J.; Khang, S.T.; Yu, J.W. Extensible compact 8-port MIMO antenna with pattern gain. Microw. Opt. Technol. Lett. 2017, 59, 236-240. [CrossRef]

3. Deng, J.Y.; Yao, J.; Sun, D.Q.; Guo, L.X. Ten-element MIMO antenna for 5G terminals. Microw. Opt. Technol. Lett. 2018, 60, 3045-3049. [CrossRef]

4. Abdullah, M.; Li, Q.; Xue, W.; Peng, G.; He, Y.; Chen, X. Isolation enhancement of MIMO antennas using shorting pins. J. Electromagn. Waves Appl. 2019, 33, 1249-1263. [CrossRef]

5. Parchin, N.O.; Basherlou, H.J.; Alibakhshikenari, M.; Parchin, Y.O.; Al-Yasir, Y.I.; Abd-Alhameed, R.A. Mobile-Phone Antenna Array with Diamond-Ring Slot Elements for 5G Massive MIMO Systems. Electronics 2019, 8, 521. [CrossRef]

6. Foschini, G.J.; Gans, M.J. On limits of wireless communications in a fading environment when using multiple antennas. Wirel. Pers. Commun. 1998, 6, 311-335. [CrossRef]

7. Johnny, M.; Aref, M.R. Blind Interference Alignment for the K-User SISO Interference Channel Using Reconfigurable Antennas. IEEE Commun. Lett. 2018, 22, 1046-1049. [CrossRef]

8. Hassan, M.M.; Rasool, M.; Asghar, M.U.; Zahid, Z.; Khan, A.A.; Rashid, I. A novel UWB MIMO antenna array with band notch characteristics using parasitic decoupler. J. Electromagn. Waves Appl. 2019, 34, 1225-1238. [CrossRef]

9. Vaughan, R.G.; Andersen, J.B. Antenna diversity in mobile communications. IEEE Trans. Veh. Technol. 1987, 36, 149-172. [CrossRef]

10. Sharawi, M.; Jan, M.; Aloi, D. Four-shaped $2 \times 2$ multi-standard compact multiple-input-multiple-output antenna system for long-term evolution mobile handsets. IET Micro. Antennas Propag. 2012, 6, 685-696. [CrossRef]

11. Deng, C.; Liu, D.; Lv, X. Tightly arranged four-element MIMO antennas for 5G mobile terminals. IEEE Trans. Antennas Propag. 2019, 67, 6353-6361. [CrossRef]

12. Ojaroudi Parchin, N.; Jahanbakhsh Basherlou, H.; Al-Yasir, Y.I.; Ullah, A.; Abd-Alhameed, R.A.; Noras, J.M. Multi-band MIMO antenna design with user-impact investigation for 4G and 5G mobile terminals. Sensors 2019, 19, 456. [CrossRef] [PubMed]

13. Hussain, R.; Alreshaid, A.T.; Podilchak, S.K.; Sharawi, M.S. Compact $4 \mathrm{G}$ MIMO antenna integrated with a $5 \mathrm{G}$ array for current and future mobile handsets. IET Microw. Antennas Propag. 2017, 11, 271-279. [CrossRef] 
14. Li, H.; Xiong, J.; He, S. A compact planar MIMO antenna system of four elements with similar radiation characteristics and isolation structure. IEEE Antennas Wirel. Propag. Lett. 2009, 8, 1107-1110. [CrossRef]

15. Hassan, T.; Khan, M.U.; Shoaib, N.; Hussain, R.; Sharawi, M.S. Correlation Reduction in a 4-Element MIMO Antenna using Partially Reflective Surface. In Proceedings of the 2019 13th European Conference on Antennas and Propagation EuCAP, Krakow, Poland, 31 March-5 April 2019; pp. 1-4.

16. Karimian, R.; Soleimani, M.; Hashemi, S. Tri-band four elements MIMO antenna system for WLAN and WiMAX application. J. Electromagn. Waves Appl. 2012, 26, 2348-2357. [CrossRef]

17. Zhang, S.; Zetterberg, P.; He, S. Printed MIMO antenna system of four closely-spaced elements with large bandwidth and high isolation. Electron. Lett. 2010, 46, 1052-1053. [CrossRef]

18. Chen, S.; Chiang, C.; Hsu, C.G. Compact Four-Element MIMO Antenna System for 5G Laptops. IEEE Access 2019, 7, 186056-186064. [CrossRef]

19. Abed, A.T.; Jawad, A.M. Compact Size MIMO Amer Fractal Slot Antenna for 3G, LTE (4G), WLAN, WiMAX, ISM and 5G Communications. IEEE Access 2019, 7, 125542-125551. [CrossRef]

20. Anguera, J.; Andújar, A.; Mateos, R.M.; Kahng, S. A $4 \times 4$ MIMO multiband antenna system with non-resonant elements for smartphone platforms. In Proceedings of the 2017 11th European Conference on Antennas and Propagation (EUCAP), Paris, France, 19-24 March 2017; pp. 2705-2708.

21. Votis, C.; Tatsis, G.; Kostarakis, P. Envelope correlation parameter measurements in a MIMO antenna array configuration. Int. J. Commun. Netw. Syst. Sci. 2010, 3, 350. [CrossRef]

22. Chae, S.H.; Oh, S.k.; Park, S.O. Analysis of mutual coupling, correlations, and TARC in WiBro MIMO array antenna. IEEE Antennas Wirel. Propag. Lett. 2007, 6, 122-125. [CrossRef]

23. Levitas, B.; Drozdov, M.; Naidionova, I.; Jefremov, S.; Malyshev, S.; Chizh, A. UWB system for time-domain near-field antenna measurement. In Proceedings of the 2013 European Microwave Conference, Nuremberg, Germany, 6-10 October 2013; pp. 388-391.

24. Chen, Q.; Lin, H.; Wang, J.; Ge, L.; Li, Y.; Pei, T. Single ring slot-based antennas for metal-rimmed 4G/5G smartphones. IEEE Trans. Antennas Propag. 2018, 67, 1476-1487. [CrossRef] 